\title{
Development of a registration system for genetic counsellors and nurses in health-care services in Europe
}

\author{
Milena Paneque ${ }^{\star, 1,2}$, Ramona Moldovan ${ }^{2,3}$, Christophe Cordier ${ }^{2,4}$, Clara Serra-Juhée ${ }^{2,5,6}$, Irene Feroce ${ }^{2,7}$, \\ Debby Lambert ${ }^{2,8}$, Inga Bjørnevoll ${ }^{2,9}$ and Heather Skirton ${ }^{2,10}$ \\ European Journal of Human Genetics (2016) 24, 312-314; doi:10.1038/ejhg.2015.234; published online 4 November 2015
}

\section{INTRODUCTION}

The first genetic counsellors were employed in Europe in the 1980s, and since then the professionalisation of the role has developed rapidly. ${ }^{1}$ Here we summarise the work to establish a registration process to ensure an appropriate level of competence in the profession and common professional standards in Europe.

The process began in 2006, when members of the Education Committee of the European Society of Human Genetics (ESHG) and the EuroGentest project prepared a document 'Core competences in genetics for health professionals in Europe', which included the competences required of genetic nurses and counsellors. The education and training required for genetic counsellors in Europe was heterogeneous and most countries had not developed standards for education, professional practice, and registration. Some countries had specific programmes in genetic counselling - with significant differences among them regarding duration or clinical training - but most countries had not. An informal network of genetic counsellors and nurses from 23 European countries was initiated. ${ }^{3}$ Later on, in 2009 the ESHG set up an Ad Hoc Genetic Nurse and Counsellor Accreditation Committee in order to support the work of ensuring adequate standards of practice for genetic counsellors. This committee developed a set of professional standards for education and a code of practice. It proposed that the educational pathway for genetic counselling professionals should be at master level, and a European curriculum for genetic counselling master programmes was prepared. ${ }^{3,4}$ The Ad Hoc committee assessed the courses offered in Europe and decided that those at Cardiff (UK), Manchester (UK), Marseille (France), Barcelona (Spain), Porto (Portugal), and Cluj (Romania) fully complied with the 2006 European core curriculum for genetic counsellors.

In 2012 the Ad Hoc committee became part of the new European Board of Medical Genetics (EBMG). The purpose of the EBMG is to establish professional standards of education, training, and practice in human, and medical genetics and genetic counselling.

\section{BUILDING A SYSTEM FOR PROFESSIONAL REGISTRATION}

The EBMG Professional Branch for genetic nurses and counsellors focused on structuring a process for registration of genetic counsellors and nurses practising in Europe. This included defining many procedures and concepts, such as the different routes of access for registration (ie, via approved MSc programmes; national route and grandfather clauses) and the evidence required of applicants.

There are currently three grandfather clauses that allow the access of experienced genetic counsellors to registration that take into consideration both their formal education and clinical practice. Grandfather A is for professionals who completed a 2-year master degree in genetic counselling and worked as genetic counsellors for at least 3 years full time; grandfather $\mathrm{B}$ is for professionals who undertook a specific course in genetic counselling (other than an approved master programme) and worked as genetic counsellors for at least 4 years full time; and grandfather $\mathrm{C}$ for professionals who do not have any specific course in genetic counselling but have a minimum of 5 years experience full time.

At this time, the Branch also started reviewing national genetic counselling certification/registration systems outside Europe. Where a rigorous national system of registration exists, practitioners who are already fully registered and work in Europe for at least 1 year may apply for European registration without additional assessment. The Genetic Counsellor Professional Branch Board of the EBMG already approved the reciprocity between five national certification boards as consistent with the standards of the EBMG register. Approved registration systems are operating in United Kingdom, USA, Canada, South Africa, and Australasia.

One of the EBMG's tasks was to define guidelines for registration applicants and to discuss the evidence required for assessing competences. Detailed information on all aspects of the process was produced and posted on the EBMG website to facilitate access by applicants (www.eshg.org/471.0.html).

${ }^{1}$ Centre for Predictive and Preventive Genetics (CGPP) and UnIGENe, IBMC, i3S-Instituto de Investigação e Inovação em Saúde, Universidade do Porto, Porto, Portugal; ${ }^{2}$ Genetic Nurse and Counsellor Professional Branch Board, European Board of Medical Genetics, Vienna, Austria; ${ }^{3}$ Department of Psychology, Babeş-Bolyai University, Cluj-Napoca, Romania; ${ }^{4}$ Department of Oncology and Haematology, CHRU Strasbourg, Strasbourg, France; ${ }^{5}$ Genetics Unit, Universitat Pompeu Fabra-Hospital del Mar Research Institute (IMIM), Barcelona, Spain; ${ }^{6}$ Centro de Investigación Biomédica en Red de Enfermedades Raras (CIBERER), Instituto de Salud Carlos III, Madrid, Spain; ${ }^{7}$ Division of Cancer Prevention and Genetics, European Institute of Oncology, Milan, Italy; ${ }^{8}$ National Rare Disease Office, Mater Misericordiae University Hospital, Dublin, Ireland; ${ }^{9}$ Department of Pathology and Medical Genetics, St. Olavs University Hospital, Trondheim, Norway; ${ }^{10}$ School of Nursing and Midwifery, Plymouth University, Plymouth, UK

${ }^{*}$ Correspondence: Professor M Paneque, IBMC-Institute for Molecular and Cell Biology, UnIGENe and Centre for Predictive and Preventive Genetics (CGPP), Universidade do Porto, Rua do Campo Alegre, 823, 4150-180 Porto, Portugal. E-mail: milenaph@ibmc.up.pt or panequita@yahoo.es

Received 24 July 2015; revised 25 September 2015; accepted 1 October 2015; published online 4 November 2015 
Evidence required may differ depending under which route the applicant is applying (Table 1). However, evidence generally includes references, a case $\log$ of 50 cases and evidence of continuing professional development (at least $30 \mathrm{~h}$ per year). Two case studies focused on counselling skills and ethical issues are also required. Under the grandfather clause (which operates until 2018) additional evidence may be required. Further details are available on the EBMG website.

\section{AN OVERVIEW OF THE FIRST 2 YEARS}

The registration system was launched at the ESHG meeting in Paris in 2013. The registration system is a two-part process. Applicants submit their intention to register and their eligibility is assessed. An application is eligible if the candidate meets the eligibility requirements, namely appropriateness of the chosen route and adequate evidence of their competence. Applicants who are eligible are asked to submit a complete portfolio.

A short summary of the applications received during the first 2 years shows that registered professionals at the time of application have a mean of 8.5 years of experience. Ninety per cent are currently working in genetic health-care services, whereas $5 \%$ are employed in education and $5 \%$ in companies offering genetic tests.

Registration has been awarded to professionals from the UK (18\%), France (18\%), Spain (18\%), Norway (15\%), Ireland (8\%), Italy (5\%), Switzerland (5\%), Portugal (3\%), Cyprus (3\%), Romania (3\%), Iceland (3\%), and Sweden (3\%). As expected, until now the vast majority of applications are under a grandfather clause (70\%), 25\% have a previous national registration, and only $5 \%$ used the normal route.
More information about the first 2 years of operation can be found in Table 2.

Applicant's main reasons for registering include increasing the awareness of genetic counselling profession in their own countries and facilitating the access to job opportunities in Europe as well as supporting the European registration process per se.

\section{CURRENT CHALLENGES AND FURTHER DIRECTIONS}

Although it was challenging to develop a registration system that addressed the needs of practitioners in countries with different educational, cultural, and legal systems, the process has been effective, as we currently have registrants from 12 countries.

As we receive numerous enquires about registration from practitioners in countries where there is no registration system (eg, in the Middle East and Asia), one of the current challenges is the development of a form of 'associate' registration for applicants outside Europe.

The main aim of the EBMG has been to develop and promote academic and professional standards necessary to provide competent genetic counselling services. Given the high quality of applications and the number of applicants from a wide range of countries, we strongly believe the European registration system brings real value to the profession for genetic counsellors and nurses in Europe, and could set the example for other professions. Clearly, a valuable aspect is the fact that as the vast majority of European countries do not yet have national registration systems or guidelines advising the training and practice standards of genetic counsellors, therefore, the European registration system will make an important contribution to the further development and adoption of best practice and training models.

Table 1 Evidence required according to the type of application

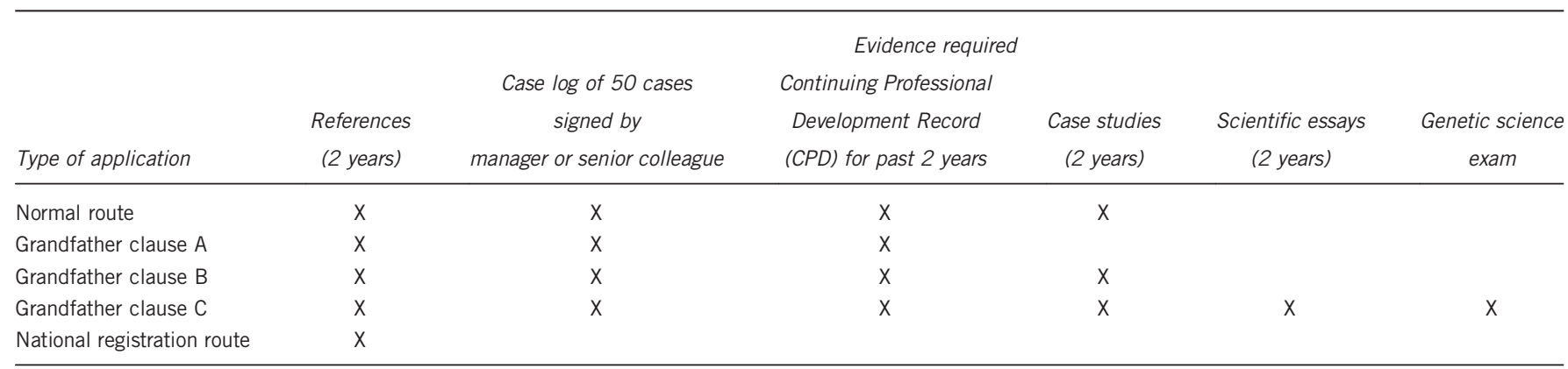

Table 2 Intentions, application eligibility, and outcomes of first 2 years of registration process

\begin{tabular}{|c|c|c|c|c|c|}
\hline Year & $\begin{array}{l}\text { Intentions } \\
\text { received }\end{array}$ & $\begin{array}{l}\text { Number assessed } \\
\text { as eligible }\end{array}$ & $\begin{array}{l}\text { Number of full } \\
\text { applications }\end{array}$ & Outcomes & Total \\
\hline 2013 & 32 & 29 & 22 & $\begin{array}{l}19 \text { approved, } 3 \text { asked to revise } \\
\text { their applications }\end{array}$ & 19 registered genetic counsellors \\
\hline 2014 & 28 & 25 & $\begin{array}{l}17+3 \text { revised submissions from } \\
\text { previous year }\end{array}$ & 20 approved & $\begin{array}{l}15 \text { registered genetic counsellors, } \\
5 \text { genetic nurses }\end{array}$ \\
\hline Total & & & & & $\begin{array}{l}34 \text { registered genetic counsellors, } \\
5 \text { registered genetic nurses }\end{array}$ \\
\hline
\end{tabular}




\section{CONFLICT OF INTEREST}

The authors declare no conflict of interest. development of core competences to support preparation of health professionals in Europe. Eur J Hum Genet 2010; 18: 972-977.

1 Cordier C, Lambert D, Voelckel MA, Hosterey-Ugander U, Skirton H: (2012). A profile of the genetic counsellor and genetic nurse profession in European countries. J Community Genet 2012; 3: 19-24.

2 Coviello D, Skirton H, Ceratto N, Lewis C, Kent A: Genetic testing and counselling in Europe: health professional's current educational provision needs assessment and potential strategies for the future. Eur J Hum Genet 2007; 15: 1203-1204.

3 Skirton H, Voelckel MA, Patch C: Using a community of practice to develop standards of practice and education for genetic counselors in Europe. J Community Genet 2010; 1: 169-173.

4 Skirton H, Lewis C, Kent A, Coviello D: The members of Eurogentest Unit 6 and ESHG Education Committee. Genetic education and the challenge of genomic medicine: (c) (i) () $\ominus$ This work is licensed under a Creative Commons (c) ${ }_{\mathrm{BY}} \mathrm{NC}$ ND Attribution-NonCommercial-NoDerivs 4.0 International License. The images or other third party material in this article are included in the article's Creative Commons license, unless indicated otherwise in the credit line; if the material is not included under the Creative Commons license, users will need to obtain permission from the license holder to reproduce the material. To view a copy of this license, visit http://creativecommons.org/licenses/by-nc-nd/4.0/ 